\title{
Conceptualizing 'Other' in the Context of Mizo Identity
}

\author{
Zarzosanga \\ Department of Political Science, Government Serchhip College, Serchhip, Mizoram, 796181 \\ India
}

Corresponding author. E-mail: zara.pachuau85@gmail.com

https://doi.org/10.12982/CMUJASR.2021.001

Editor:

Yos Santasombat,

Chiang Mai University, Thailand

Article history:

Received: September 25, 2021

Revised: November 30, 2021

Accepted: November 30, 2021

\begin{abstract}
The concepts of 'Us' and 'Others' has been a persistent factor in the history of Mizo identity formation. The perception of the 'other' in the Mizo psyche has shaped and molded the growth and evolution of Mizo identity throughout the precolonial, colonial and post-colonial periods. This article aims to trace and examine the origin of the Mizo perception of 'others' and to evaluate how it has affected the realization and conception of Mizo identity among the Mizo themselves, vis-à-vis a pan-Indian identity. In so doing, the article outlines the theoretical perception of the term 'identity', the roots of the conception of Mizo identity in the pre-colonial period and how that identity was shaped by the conception of the 'other' in the early Mizo psyche. The article then traces the evolution of that 'other' during the colonial period and its subsequent impact on the Mizo identity itself as well as how it differed from the pre-colonial conception of the 'other'. The article concludes by analyzing the further growth and evolution of Mizo identity in the post-colonial period and how that evolution again affects the Mizo conception of the 'other' and vice versa, and highlights the future sociopolitical and cultural implications of that conception in the context of Mizo identity perception.
\end{abstract}

Keywords: Britain, Christianity, Identity, Lushai, Mizo, Other

\section{INTRODUCTION}

The concept of identity has long been an area of contention in global discourses on society, culture and politics, and the concept's vagueness and variations in interpretation has ensured it has also long remained a constant source of academic and intellectual debate. Yet, the significance and importance of the matter and the need to assert one's identity within a larger group identity has been increasing, especially in today's multi-ethnic social and political environment. Hence, examining and re-examining the concept of identity is and always will be required in order to analyze its impacts on global sociopolitical and cultural studies. 
Identity could be defined as an outward manifestation of one's inner self, an individual's understanding of who he is and to whom and where he belongs. Identity grows, in the first place, out of a distinction between one's true inner self and an outer world of social rules and norms that does not adequately recognize that inner self's worth or dignity (Fukuyama, 2018, pp. 9-10). In the course of human history, people of all societies and ages have grappled with the problem of conforming their internal dignity, value and worth, in short, their self-esteem, with external social perceptions and social order. While the dignity of a few people is the sum of the attribute of their intrinsic worth by virtue of their varied contributions to society, the dignity of the majority of the population is identified in terms of other parameters, and this is where the difficulty of defining and identifying one's own worth, self-esteem and identity lies. Self-esteem arises out of esteem by others (Fukuyama, 2018, p. 10). Instinctively, all human beings crave recognition and that recognition requires 'others' for its manifestation. Hence, the perception of that 'other' and how that 'other' is thought to perceive a person's value, worth and selfesteem is how people came to identify their true self, in other words, who they are and who they think they are, I.e., their identity.

Understanding the concept of identity and its various implications therefore requires moving back and forth between the past and the present. Questions related to identity include the recovery of one's past and the understanding of that past in the creation of that identity (Pachuau, 2014a, p. 23). This argument is particularly true when examining Mizo identity. The history of the Mizo features clan and village-based sociopolitical administration, colonial subjugation, ethnic-based violence and other ethno-centric perceptions. The Mizo's understanding and conceptions of identity have been greatly influenced by this past history, particularly, the conflict between their primordial sense of self and their contact with Western ideals. Subsequently, this led to the conception of the 'other' in the Mizo psyche, a notion which had always characterized itself as marginal by carving out a niche within the larger canvas of the society. This Mizo conception of 'other' has been at the center of Mizo identity formulation since the early days of Mizo history. The advent of the British in the then-Lushai Hills (present day Mizoram) greatly affected the idea of what being a Mizo is and how the Mizo still conceive their identity today (Pachuau, 2014b, p. 15).

Brubaker and Cooper identified five dominant ways in which the concept of identity is deployed in the social sciences and humanities (as cited in Malesevic, 2006, pp. 27-28):

a) Identities as non-instrumental forms of social action.

b) Identities as collective phenomena of group sameness.

c) Identities as deep and foundational forms of selfhood.

d) Identities as interactive, processual, contingent products of social action.

e) Identities as fluctuating, unstable and fragmented modes of the self.

Based on the above parameters, this article analyzes how Mizo identity emerged from formulations of the 'other' as a basis for conceiving self-identity as well as group identity in the various stages of Mizo history, I.e., during the precolonial, colonial and post-colonial periods. 


\section{THE CONCEPT OF ‘OTHER’ AND MIZO IDENTITY IN THE PRE-COLONIAL PERIOD}

The concept of Mizo identity continues to be a matter of academic and intellectual debate. The root and origin of the Mizo tribe is shrouded in mystery and so is the definition of Mizo identity, comprehensive of all Zo ethnic tribes.

During the pre-colonial period, which, according to the noted Mizo historian Lalthangliana, spanned for about 300 years from 1580-1890 A.D. (2014, p. 348), but which, according to another notable Mizo historian, Siama, ran for around 200 years from 1700-1889 A.D. (1953, p .65), the Mizo (then called Lushai) chiefs ruled their own respective villages independently. The chiefs were not referred to by their individual names, but, were rather identified and referred based on their clan i.e. Sailo chief, Fanai chief, Zadeng chief and so on (Liangkhaia, 2002, p. 65). The chiefs were the only source of administration and authority in their own respective villages, performing duties including the declaration of war and the conclusion of peace treaties, the selection and distribution of jhumlands for cultivation, religious and other festive activities, and most importantly, the execution of - or gift of amnesty to - villagers (Lalthangliana, 2014, p.349). The Mizo people were wholly dependent on the discretion and mercy of their chiefs for their existence and subsistence. Hence, although they were aware of the fact that they all shared common ancestry and spoke a common language, they did not seem to conceive a pan-Mizo identity, which would bind them as a homogenous ethnic group (Khiangte, 2014, p. 156). Instead, Mizo people would identify themselves as belonging to a particular clan, as having a particular chief or as a citizen of a particular village, "Kei chu mi kha mi hnam, chu mi kha mi Lal khuaa mi chu ka ni", (English: I am from so-and-so clan belonging to the village of the so-and-so chief), was their common expression of self and Mizo identity. Thus, their affiliation to a particular clan and their belonging to a particular village under a particular chief defined who they were and under whom they identified.

This same conception of identity framed the conception of the 'other' in precolonial Mizo society. As prominent Mizo writer Khiangte commented, "The early Mizo seldom asked strangers to which village they belong. Rather, they asked to whose village, I.e., to which clan chief's village they belong", (2014, p. 156). Hence, clan affiliation was given utmost importance in 'Mizo' identification which, at the same time, also shaped conceptions of who were the 'others.' Moreover, each clan had their own religious rituals and practices known as sakhua. ${ }^{1}$ The type of sakhua that the Mizo people professed differed from clan to clan.

All clans also had their separate priest, known as sadawt, to perform religious sacrifices and rituals. The chiefs had their own separate sadawt, ${ }^{2}$ who undertook the responsibility of performing all rituals and sacrifices during festivals and public gatherings. The sakhua gave identity to the tribe and it was said that the more similar

\footnotetext{
${ }^{1}$ The term Sakhua is made up of two words 'sa' and 'khua.' Sa is considered to be the transcendent being that guide, ruled upon and looked after each particular clan and family, and khua referred to the spirit that protected all the inhabitants of the village and each individual. Hence, the Mizo sakhua could not be defined as a religion in the strict sense of the term. Rather, it is the superstitions, beliefs, ethics or moral codes that governed the entire life of the Mizo people. ${ }^{2} \mathrm{~A}$ religious priest who performed all sacrificial ceremonies.

2 A religious priest who performed all sacrificial ceremonies.
} 
the rituals performed by a tribe or clan in propitiating its sakhua, the closer was the affinity between the tribes (Pachuau, 2014a, p. 179). The Mizo relied on cultural practice as the chief determinant and boundary marker of identity (Pachuau, 2014, p. 11). Since each clan had its own separate cultural and traditional practices, clan affiliations played a crucial role in the formation of the conception of Mizo identity and the notion of the 'other' in the pre-colonial Mizo psyche.

From the above observations, it could be concluded that Mizo conceptions of identity during the pre-colonial period were largely based and on the question of to which clan and village one belonged to. Isolated and devoid of contact with tribes other than the other Lushai clans, notions of who were the 'others' did not go beyond the confines of their clan identifications. Hence, during the pre-colonial period, the conception of 'being a Mizo' could be interpreted as simply belonging to a particular clan group under the rule of a particular clan chief. It was based on this assumption and conception that the Mizo distinguished themselves and defined who they were, I.e., their identity, apart from whom they considered 'other'. In other words, it was the collective phenomena of group/clan sameness and their deep and profound identification with their respective clans that defined their identity as well as their perception of who was 'other' during the pre-colonial period. It may be for this reason that while inter-clan wars were of frequent occurrence among the Mizo during this period, intra-clan wars seldom occurred.

\section{THE CONCEPT OF ‘OTHER’ AND MIZO IDENTITY DURING THE COLONIAL PERIOD}

The advent of the British in Mizoram (at that time the 'Lushai Hills') completely altered the sociopolitical dimensions of Mizo society and the Mizo polity. After Chittagong was ceded to Robert Clive in 1777, a Palian (one of the Mizo clans) chief raided Sylhet (Pachuau, 2014a, p. 92) and other Mizo chiefs commenced regularly raiding the surrounding areas of the Chittagong Hill tracts, Manipur, Silchar, Sylhet and Tripura, becoming quite troublesome for the British administrators in these areas. The raids become more and more frequent: between 1869 and 1871, there were 25 raids conducted by various Mizo chiefs in the areas just noted (Lalthangliana, 2014, p. 509). This resulted in the two British Lushai Expeditions, also known as the Chin-Lushai Expeditions, the first in 1871 and the second in 1889-1890. Besides, the annexation of upper Burma in 1885 and the establishment of a permanent outpost, Fort White, made it reasonable to annex the Lushai Hills, as it was the only piece of intervening territory between the Chittagong Hill tracts and upper Burma that was not governed by the British (Pachuau, 2014a, p. 93). The Chin-Lushai Expedition of 1889-1890 marked the formal annexation of the Lushai hills into the British Union under the Foreign Jurisdiction Act, 1890 and it was also declared as a Scheduled Area under the Scheduled District Act, 1874 (Zamawia, 2012, p. 42). In 1898, the Lushai Hills came to be administered as one of the districts of Assam (Pachuau, 2014a, p. 93).

From the very outset, the annexation of the Lushai Hills under the British Union jeopardized and altered not only the erstwhile independent character of the Mizo chiefs and their administration, but also greatly affected the conception of identity and the notion of the 'other' in the minds of the Mizo people. During the 
pre-colonial period, the Mizo chiefs did not demarcate or negotiate with other chiefs regarding the area of their jurisdictions. They did not have definitive boundary demarcations to separate and distinguish their territories. However, with the advent of the British, the Mizo chiefs, who used to be the sole source and fountain of justice in their villages, were subjugated by an unknown authority, who demarcated and fixed boundaries for administrative and security purposes at their own convenience.

These actions of the British not only undermined the authority of the chiefs, but also greatly affected the definitions of territoriality and identity among the Mizo people. The delineation of boundaries linked the people with the land in a way that was unknown in earlier times, providing scope for a broader macro identification amongst the people as well as distinguishing them from others (Pachuau, 2014a, p. 99). In the pre-colonial period, the identity of a person was dependent on which clan he belonged to and to which village he was a resident of and the notion of who constituted the 'other' was also conceptualized based on the same parameters. Besides, since all villages and their inhabitants, including chiefs, were dependent on jhumland cultivation that required frequent shifting of their villages in search of cultivable and fertile lands, the question of identity and the notion of 'other' was greatly affected by such frequent movements. During that period, a person was attached to a chief and an individual's location was not fixed, whether to territory or even a chief (Pachuau, 2014a, p. 100). In other words, people often migrated from the village of one chief to another chief's village and their identity and conception of 'other' also shifted with their new settlement. Thus, their identity was not confined or defined by a fixed settlement or territory. However, the British confined the people through their demarcation of fixed boundaries and by bringing them under a single and uniform colonial administration. It was from this instance that the perceptions of the Mizo people of their own identity began to undergo a gradual and long-lasting change.

Moreover, the classification of the Mizo as 'tribals' by the British administration greatly affected conceptions of identity among the Mizo people. In fact, bounded notions of identity were consolidated through the practice of classification: the 'tribes' recorded initially as 'marauding hordes' were in time given an identity, I.e., a tribal identity (Pachuau, 2014a, p. 102). Hence, from this point on, the Mizo were officially identified and referred to as the 'Lushai,' a group of tribal people, an exonym coined by the British administration and not by the Mizo themselves. ${ }^{3}$

Thus, the advent of the British into the Lushai hills and the subsequent system of administration that they imposed upon the Mizo people began to change perceptions of Mizo identity, not only those of the colonizers, but also of the Mizo themselves. The British administered the Mizo people under three types of administration. The first type was an autocratic administration, where the Superintendent assumed the role of the administrator of law and order, which was previously assumed by the Mizo chiefs. The second type of administration was what could be referred to as a theocratic administration, spearheaded by the Christian missionaries, and the third type of administration was customary administration,

\footnotetext{
${ }^{3}$ The term 'Mizo' had been used commonly by the Mizo people, which can be seen from the fact that the first local published newspaper, Mizo Chanchin Laisuih, used the term in 1898.
} 
whereby the Mizo chiefs continued their rule under the aegis of the British Government (Hermana, 2000, p. 4). Now, being a subject of the mighty British Empire, they began to conceive themselves as having a common Mizo identity, rather than clan-based or village-based identities during the pre-colonial period. Subsequently, the notion of the 'other' began to be conceived of in the context of a Mizo identity, inclusive of all clans in contrast to their colonial rulers, whom they often referred to as Mi ngo ho (white people) and Vais, "the people from outside their areas", the subordinates who aided the British officials in administering the Mizo people. They no longer saw other Mizo clans as constituting the 'other' as was the case in the pre-colonial period.

Another notable product of the British colonization of the Lushai Hills which again had a far-reaching impact on the conception of Mizo identity was the coming of Christianity to the hills. The first Christian missionaries to enter the Lushai Hills on a mission were J.H. Lorrain and F.W. Savidge, both of whom were missionaries of the Indian Aborigines Mission, also known as the Arthington Mission. They reached the village of Sairang on the outskirts of Aizawl on 11 January, 1894 (Lloyd, 1991, pp. 25-26). Other missionaries subsequently followed them in later years.

The introduction of an unknown religion with its separate sets of principles and teachings, which would come to alter the whole social and psychological perception of Mizo society, was not initially welcomed by the Mizo. In the first years of the Christian missions, the missionaries/evangelists were met with hostility, not merely as Christians but as strangers to the villages they visited (Lloyd, 1991, p. 58). Early Mizo converts to Christianity faced even more hostility than the missionaries themselves received. They were regarded as daft, as wandering beggars, as lazy or homeless vagrants (Lloyd, 1991, p. 59). At this juncture, the perception of the 'other' was extended to include Mizo Christian converts, who were seen as conspiring and collaborating with the foreigners, the so-called 'mi ngo ho,' and were heavily criticized, condemned, ridiculed and even expelled from their homes and villages because of their new faith. They even had difficulties finding suitable wives because Christian girls were so few and the heads of the families were reluctant to let their daughters marry Christians (Lloyd, 1991, p. 59).

The ultimate rejection or fate met by many of the early converts were the socalled hnawhchhuah and tuithlar. The term hnawhchhuah mainly pertained to the expulsion of a person from the family and the village. However, tuithlar not only implies the expulsion and rejection of an individual from the family or village, but also implies the expulsion from the clan to which they belong. In other words, some early Mizo Christian converts lost their Mizo identity by professing a Christian faith and were considered alien by their own families, clans, villages and even by their chiefs. The abhorrence of Christianity by the Mizo chiefs was primarily due to their belief that the Christian religion was the religion of westerners and therefore, was their instrument of changing Mizo beliefs with Western ideals (Siama, 1953, p. 152). Hence, the advent of Christianity greatly altered Mizos' understandings of their identity and consequently, their perception of who were 'others' in their community. As a result, between the time of launching their mission in 1891 and 1899, J. H. Lorrain and F. W. Savidge were able to successfully convert only two indigenous Mizo, namely, Khuma and Khara, of whom, Khara later reverted to his old beliefs. 
Thus, the twentieth century began only with one Mizo Christian (Kipgen, 1996, p. 209).

However, as Christianity slowly and gradually permeated the Mizo society, more and more converted to the new religion and again, this phenomenon had a profound impact on the Mizo psyche, their conception of their own identity and how they perceived 'others.' By 1951 the Mizo Christian population stood at 157,575 out of a total population of 196,202 , representing 80.3 percent of the total population of the Lushai Hills (Kipgen, 1996, p. 209). Thus, within a mere period of roughly 60 years since the advent of Christianity, virtually all the Mizo people had abandoned their old religious practices, rituals and sacrificial ceremonies and were converted to Christianity. This remarkable phenomenon, yet again, had another profound impact on the conception of Mizo identity. By the early 1950s, as one of the early Mizo historians, Siama noted, "It had become a shameful thing not to be a Christian" (1953, p. 169).

Hence, with a majority of the Mizo converted to Christianity, a new conception of Mizo identity, namely, 'Mizo-Christian identity' began to emerge in the middle of the twentieth century. By then, Mizo identity had become so tightly intertwined with Christian ideals that being Mizo meant being perceived as Christian. This was mainly due to the fact that the majority, if not all, of the traditional and customary Mizo practices, religious rituals, customs, traditions and even festivals were shunned and prohibited by the new Christian religion (Tochhawng, 2011, p. 162). In other words, Christianity had done away with the traditions and practices of the Mizo during the pre-colonial period, which served as the main basis of their identity and culture. Religion now became the main denominator of their identity, the defining characteristic of who they were. The missionaries brainwashed early Mizo Christian converts with the perception that abstaining from traditional Mizo festivals and practices was what identified or what distinguished them from non-believers (Tochhawng, 2011, pp. 165-166). Being a Christian became synonymous with being Mizo, and thereby, the conception of the 'other' also became largely conceived of through the prism of a Mizo-Christian perspective.

The British administration during the colonial period and the work of Christian missions and missionaries left profound and indelible marks on the sociological and psychological perceptions of Mizo people on their identity. It could be concluded that these two phenomenon may have modernized Mizo society, politics and mindsets, but also affected a paradigm shift in their conceptions of identity, which influenced the Mizo's conceptions of the 'other'. By this time, due to the fact that the majority of Mizos were Christians, they came to largely conceive of non-Mizo people as being non-Christians.

\section{THE CONCEPT OF THE ‘OTHER’ AND MIZO IDENTITY IN THE POST-COLONIAL PERIOD}

The end of British rule in India and the subsequent independence of India further presented another paradigm shift in the conception of Mizo identity and their perception of the 'other.' The Lushai Hills was among the newly created Autonomous Hills Districts of Assam in 1952. With the political consciousness of the Mizo people gradually developing, culminating in the establishment of the first 
Mizo political party, namely, the Mizo Commoner's Union (later renamed Mizo Union) in 1946, the Mizo people started to organize and administer themselves through their democratically elected representatives. This new development brought with it a new sense of consciousness, which, hitherto, had not been prevalent among the Mizo people, I.e., ethnic consciousness. In effect, this was largely the consequence of colonial rule and the corresponding administration of the Lushai Hills by the newly independent Indian Government thereafter. It has been argued by some that, in the wake of the anti-colonial struggle that formed and created an Indian nationalism, the Northeast and especially the areas that constitute the hills, were largely excluded from the building of the collective Indian consciousness (Pachuau, 2014a, p. 52). As a result, during the Freedom Movement, the Northeast region, including the Lushai Hills, was largely unheard of, as such that the people, whom the British called "tribals" (nomenclature used by the Indian Government even after independence), did not develop a bond or connection with the Freedom Movement during the course of the struggle. Moreover, the creation of states based on linguistic lines by the Indian Government further marginalized the already culturally different tribes of the Northeast in the post-Independence period.

With language becoming a key cultural trait in defining and determining one's identity in the post-independence period, in the case of the Northeast, where so-called 'tribes' speak languages that are either Tibeto-Burman or Mon-Khmer, vastly different from the Indo-Aryan or Dravidian speech of the dominant subcontinent population, the idea of difference is even more strident (Pachuau, 2014a, p. 52). Thus, apart from the religious and clan-based definitions of identity of the Mizo people, new elements were added in the form of language and ethnicity, which resulted in the formulation of a new conception of Mizo identity apart from the already conceived Mizo-Christian identity. As a result, the Mizo's conception of who constituted the 'other' also came to be largely conceived of as those non-tribal, non-Christian believers. Hence, in the Northeast, ethnic mobilization on the basis of difference from the larger populations is couched in racial or linguistic terms, as well as those of religion (Pachuau, 2014a, p. 52).

Moreover, the sense of isolation and neglect by the Indian Government among the Mizo people in the post-independence period greatly contributed to further changes in their perception of Mizo identity and the 'other'. The government's economic policy for the Northeast was predicated on the State's need to extend its power and influence, and was not necessarily pursued out of concern for the people of the region (Pachuau, 2014a, p. 54). This intent was felt even more so in the Mizo Hills District, ${ }^{4}$ which was one of the remotest parts of the Northeast region. The situation was further aggravated by the Mizo Hills mautam (a famine caused by rats breeding during a periodic flowering of bamboo) ${ }^{5}$ during 1959-1960. The response of the central Indian Government and the Assam Government to the

\footnotetext{
${ }^{4}$ The nomenclature of Lushai Hills was officially changed to the Mizo Hills District with the elevation of the Hill District into an Autonomous District Council under the state of Assam in 1952.

5 The periodic flowering of bamboo is alleged to occur every 50 years. The bamboo flowers were consumed by rats and rodents, resulting in the sudden increase in rodent population that ultimately destroyed crops, thereby causing a widespread famine.
} 
famine were largely seen as unsatisfactory and not addressing the core problem. The Mizo National Famine Front (MNFF), a voluntary organization established for the purpose of aiding famine relief efforts of the government (Zamawia, 2012, p. 162), voiced its concerns regarding the delayed famine relief efforts and even condemned the Mizo Union, the then-ruling political party in the Mizo Autonomous District Council. They organized demonstrations demanding immediate action on the part of the Government towards famine relief efforts and even organized Tam Khawmpui Lian (a Famine General Assembly) on 9 March, 1960 at Aizawl, and urged all Mizo people to attend the function accordingly (Zamawia, 2012, p. 162).

Such was the extent of discontentment and dissatisfaction against the Mizo Union at the District Council level and the Assam State Government at the state level that a new political party was established on 28 October, 1961, which was named the Mizo National Front (MNF) by the erstwhile leaders of the MNFF, one of which was Laldenga, who became the founding President of the newly formed political party (Zamawia, 2012, p. 169). The leaders of the newly formed MNF party were already popular among the public as a result of their efforts as leaders of the MNFF during the years of famine. Hence, the party quickly gained popularity among the public. The rise of the MNF is noteworthy because it mirrored the growing political and ethnic dimensions of Mizo identity which subsequently resulted in the launching of the Mizo Independence Movement in 1966. In galvanizing the Mizo people to stand behind them in their claim for an independent nation, the MNF aroused the ethnic and religious sentiments of the Mizo people, the very basis of their definition of identity and their conception of 'other' in previous years. In other words, the MNF exploited the famine situation by framing the Mizo's cultural and religious differences from the majority population in India as incompatible with Mizo identity (Pachuau, 2014a, p. 129).

By projecting the Indian Government as the government of the non-believers and their main oppressor, the MNF further radicalized the concept of 'other' by instilling an anti-sentiment in the minds of the Mizo people. As stated earlier, apart from appealing to the ethnic consciousness of the Mizo people for their cause, with their famous slogan, Pathian leh Kan Ram Tan (For God and Our Nation), the MNF aroused the religious sentiments of the Mizo people as well. In effect, they fought as insurgents for a form of Mizo nationalism within which guarding Christianity is the heart of the struggle (Guite, 2020, p. 356). The Independence Movement, ethnic identity and nationalism, not only religious affiliation, have all contributed to the definition of Mizo identity and Mizo conceptions of the 'other.' Even so, after the end of the Movement with the signing in 1986 of the Memorandum of Settlement, popularly known as the Mizo Peace Accord, being a Christian continues to remain a crucial element of Mizo identity. Today, matters perceived as a threat to religion or religious issues are conceived as a threat to the ethnicity and identity of the Mizo and vice versa, which cam be seen from the Mizo's hostile attitude towards the Brus or Reangs, a largely Christian minority tribe, the predominantly Buddhist Chakmas, and the Hindu-dominated Gorkhas, another minority group in Mizoram. Thus, with the conception of Mizo identity being defined and identified more and more on the basis of ethnic and religious grounds, the Mizo's perception of 'others' has also come to rely on Mizo ethno-centrism and a Mizo Christian perspective, a faith which has become one of the foremost dominant factors of Mizo identity today. 


\section{CONCLUSION}

The evolution of Mizo identity from the pre-colonial period to the present day has been constantly changing and evolving along with the sociopolitical and cultural context characterizing Mizo society. In the pre-colonial period, identity and the conception of 'other' was limited to the confines of clan and village-based affiliations. However, the colonial period presented a different picture. During the colonial period, the British 'divide and rule' system contributed to consolidating the Mizo into a common identity under one umbrella, an identity that came into being following the creation of the Mizo Autonomous District Council in 1952 (Patnaik, 2016, p. 627). Moreover, the process of Christianization by missionaries also greatly contributed to the formation of a Christian-Mizo identity in the colonial period.

Owing to the resurgence of ethnic nationalism and a religious consciousness due to the Independence Movement, the Mizo conceptualization of identity today has come to be largely based on ethnic lines and religious affiliations. In fact, the solidarity of the Mizo people, today, is on the basis of conversion to Christianity (Patnaik, 2016, p.625). Christianity provided a separate identity from the so-called 'head hunters' of the pre-colonial period (Patnaik, 2016, p. 625). The notion of who constituted the 'other' also came to be conceptualized and perceived through the lens of an ethnic Mizo-Christian identity, which had its roots in the pre-colonial society and which transformed and adapted during the course of history to assume its present conception. The Christian Church, as an institution, has become a resource for ethnic identification today (Pachuau, 2014a, p. 157).

Lastly, given the fact that Mizo society has come to be deeply rooted and continues to identify with Christian principles and ideals, as well as having an ethnic consciousness, particularly, under the aegis of the powerful ethnic-based organization, the Young Mizo Association, ${ }^{6}$ the Mizo's conception of the 'other' also seems destined to be grounded and conceptualized in the contexts of such ethnic and religious lines in the near and far future. In short, the concept of Mizo identity and the perception of the 'other' in the post-colonial period could be said to be the result of interactive, processual and contingent products of social action, shaped and affected by the exigencies of time.

\footnotetext{
${ }^{6}$ The Young Mizo Association was initially established by the name of the Young Lushai Association (YLA) by the Christian Missionaries back in 1935. Today, the YMA has the largest membership base among all civil society organizations in Mizoram and has been one of the most influential Non-Governmental Organization in the state. The nature of its establishment and the history of its evolution could be seen as a prime example of how religion and ethnic consciousness have a deep impact in the social and psychological set up of the Mizo people and the Mizo society.
} 


\section{DECLARATION OF CONFLICTING INTERESTS}

The author declared no potential conflicts of interest with respect to the research, authorship and/or publication of this article.

\section{FUNDING}

The author received no financial support for the research, authorship and/or publication of this article.

\section{REFERENCES}

Fukuyama, F. (2018). Identity: Contemporary Identity Politics and the Struggle for Recognition. Profile Books.

Guite, L. (2020). National and Religious Identity of the Mizo with Special Reference to Mizoram Insurgency. Research Journal of Humanities and Social Sciences, 11(4), 355-360. https:/ / doi.org/10.5958/2321-5828.2020.00056.X

Hermana, C. (2000). Zoram Politics Thli Tleh Dan Volume-I. Presscom Publications.

Khiangte, L. (2014). Mizo Nihna leh Hnam Inpumkhatna (Mizo Identity and Unification). In B. Lalnunzira (Ed.), Mizo Identity (pp.154-165). Students Christian Movement of India, Aizawl Theological College Unit.

Kipgen, M. (1996). Christianity and Mizo Culture. Mizo Theological Conference.

Lalthangliana, B. (2014). India, Burma leh Bangladesha Mizo Chanchin. Swapna Printing Works.

Liangkhaia (2002). Mizo Chanchin. Mizoram Publication Board.

Lloyd, M.J. (1991). History of the Church in Mizoram (Harvest in the Hills). Mizoram Publication Board.

Malesevic, S. (2006). Identity as Ideology: Understanding Ethnicity and Nationalism. Palgrave Macmillan.

Pachuau, J.L.K. (2014). Being Mizo: Identity and Belonging in North East India. Oxford University Press.

Pachuau, J.L.K. (2018). Mizo Identity Bihchianna (Analyzing Mizo Identity). In B. Lalnunzira (Ed.), Mizo Identity Bihchianna (pp. 8-16). Students Christian Movement of India, Aizawl Theological College Unit.

Patnaik, J.K. (2016). Mizo Identity and Indianisation: A Case of Conflict Transformation in Mizoram. Indian Journal of Public Administration, LXII(3), 623635.

Siama, V.L. (1953). Mizo History. Lengchhawn Press.

Tochhawng, R. (2011). Mizo Culture leh Sakhuana. Bangalore Mizo Association.

Zamawia, R. (2012). Zofa te Zin Kawngah Zalenna Mei a Mit Tur a Ni Lo. Lengchhawn Press. 